Original Research Paper

\title{
Pelatihan Pengisian Instrumen Akreditasi Untuk Peningkatan Mutu Evaluasi Diri Sekolah/Madrasah Pada Kelompok Kerja Madrasah Aliyah Wilayah IV
}

\author{
Agus Ramdani ${ }^{1 *}$, A. Hari Witono ${ }^{1}$, Sukardi $^{1}$ \\ ${ }^{1}$ Program Studi Magister Administrasi Pendidikan, Pascasarjana, Universitas Mataram
}

*Corresponding Author:

Agus Ramdani, Program

Studi Magister Administrasi

Pendidikan, Pascasarjana,

Universitas Mataram,

Indonesia;

Email:

aramdani07i@unram.ac.id

\begin{abstract}
Abstrak: Sekolah/madrasah yang berkualitas pada jenjang pendidikan dasar dan menengah adalah sekolah yang telah memenuhi 8 Standar Nasional Pendidikan. Salah satu upaya untuk mengetahui pemenuhan standar tersebut adalah melalui Evaluasi Diri Sekolah (EDS). Dalam implementasinya, EDS juga digunakan sebagai langkah persiapan bagi sekolah/madrasah dalam proses pemenuhan Standar Nasional Pendidikan melalui akreditasi. Pada kenyataannya guru dan kepala sekolah mengalami kesulitan dalam pengisian instrumen akreditasi yang dikembangkan oleh BAN S/M, hal ini disebabkan antara lain oleh belum meratanya sosialisasi tentang sistem akreditasi terutama pada sekolah/madrasah swasta yang perlu mendapat perhatian lebih. Sehubungan dengan hal tersebut, perlu ada upaya yang lebih intensif untuk mensosialisasikan sistem akreditasi pada sekolah/madrasah terutama pada bagian evaluasi diri sekolah/madrasah. Pengabdian pada masyarakat ini dilaksanakan dengan tujuan untuk: 1) meningkatkan pemahaman guru dan kepala sekolah tentang konsep evaluasi diri dalam rangka penjaminan mutu internal sekolah/madrasah, 2) meningkatkan keterampilan guru dan kepala sekolah dalam mengisi instrumen akreditasi sebagai bagian dari pelaksanaan evaluasi diri sekolah/madrasah, dan 3) meningkatkan kesadaran guru dan kepala sekolah tentang pentingnya penjaminan mutu internal melalui evaluasi diri sekolah/madrasah yang dilakukan secara berkesinambungan. Permasalahan yang menjadi fokus kegiatan pengabdian pada masyarakat ini adalah terbatasnya kemampuan guru dan kepala sekolah/madrasah dalam mengisi instrumen akreditasi yang dikembangkan oleh Badan Akreditasi Sekolah/Madrasah. Selain itu, kemampuan untuk menganalisis keterkaitan antara instrumen akreditasi, petunjuk teknis pengisian instrumen akreditasi, dan instrumen pengisian data dan informasi pendukung yang masih perlu ditingkatkan. Strategi yang diterapkan dalam kegiatan ini antara lain adalah: 1) sosialisasi dan focus group discussion tentang materi evaluasi diri sekolah sebagai bagian dari pelaksanaan penjaminan mutu internal sekolah, 2) pendampingan dalam pengisian instrumen akreditasi yang dikembangkan BAN S/M, dan dilanjutkan dengan diskusi refleksi. Luaran yang telah dihasilkan melalui kegiatan ini adalah: 1) terlaksananya kegiatan sosialisasi dan diskusi terpusat pada materi instrumen akreditasi jenjang SMA/MA, 2) terlaksananya kegiatan pendampingan pengisian instrumen akreditasi, dan 3) tersusunnya artikel yang dipublikasikan pada jurnal pengabdian pada masyarakat.
\end{abstract}

Kata Kunci: instrument akreditasi, evaluasi diri sekolah, penjaminan mutu internal

\section{Pendahuluan}

Pemenuhan Standar Nasional Pendidikan sebagaimana tertuang dalam Undang-undang Nomor 20 Tahun 2003 Pasal 50 ayat (2) dinyatakan bahwa pemerintah menentukan kebijakan nasional dan standar nasional pendidikan untuk menjamin mutu pendidikan nasional. Selanjutnya untuk mengetahui kelayakan satuan pendidikan perlu dilakukan proses akreditasi sebagaimana tertuang dalam Undang-undang Nomor 20/2003 tentang Sisdiknas pada pasal 60 ayat (1), yaitu akreditasi dilakukan untuk menentukan kelayakan program dan/atau satuan pendidikan pada jalur pendidikan 
formal dan non-formal pada setiap jenjang dan jenis pendidikan dilakukan oleh pemerintah dan/atau lembaga mandiri yang berwenang sebagai bentuk akuntabilitas publik.

Menurut Permendiknas Nomor 19 Tahun 2007 tentang Standar Pengelolaan oleh Satuan Pendidikan Dasar dan Menengah sekolah wajib melakukan evaluasi diri terhadap kinerja sekolah dalam rangka pelaksanaan Standar Nasional Pendidikan. Hal ini secara tegas juga tertuang dalam Permendiknas Nomor 63 Tahun 2009 Pasal 1 ayat (2) yang menyatakan bahwa penjaminan mutu pendidikan adalah kegiatan sistemik dan terpadu oleh satuan atau program pendidikan, penyelenggara satuan atau program pendidikan, pemerintah daerah, pemerintah, dan masyarakat untuk meningkatkan kecerdasan kehidupan bangsa melalui pendidikan.

Evaluasi Diri Sekolah (EDS) merupakan proses evaluasi diri sekolah yang bersifat internal yang melibatkan pemangku kepentingan untuk melihat kinerja sekolah berdasarkan Standar Nasional Pendidikan (Pusat Pengembangan Tenaga Kependidikan, 2015). Hasil EDS digunakan sebagai dasar penyusunan Rencana Kerja Sekolah dan sebagai masukan bagi perencanaan investasi pendidikan tingkat kabupaten/kota dan pemangku kepentingan lainnnya. EDS merupakan bagian dari pemetaan mutu sekolah. Peta mutu ini memberikan data awal pencapaian standar nasional pendidikan. Evaluasi diri sekolah dalam konteks akreditasi dapat dilakukan menggunakan instrumen akreditasi yang telah dikembangkan oleh Badan Akreditasi Nasional Sekolah/Madrasah (BAN S/M). BAN$\mathrm{S} / \mathrm{M}$ telah mengembangkan instrumen akreditasi berdasarkan delapan standar yang kemudian dijabarkan dalam bentuk indikator-indikator yang mengacu pada ketercapaian masing-masing standar. Instrumen akreditasi ini dari waktu ke waktu mengalami perubahan guna menyesuaikan dengan perkembangan dunia pendidikan.

Hasil observasi yang dilakukan pada sekolah/madrasah di wilayah lombok barat, diperoleh informasi bahwa, 1) guru dan kepala sekolah mengalami kesulitan dalam pengisian instrumen akreditasi yang dikembangkan oleh BAN $\mathrm{S} / \mathrm{M}, 2$ ) belum meratanya sosialisasi tentang sistem akreditasi terutama pada sekolah/madrasah swasta yang perlu mendapat perhatian lebih. Berkaitan dengan permasalahan tersebut maka solusi yang ditempuh melalui kegiatan pengabdian pada masyarakat ini adalah dengan: 1) sosialisasi dan focus group discussion tentang materi evaluasi diri sekolah sebagai bagian dari pelaksanaan penjaminan mutu internal sekolah, 2) pendampingan dalam pengisian instrumen akreditasi yang dikembangkan BAN S/M, dan dilanjutkan dengan diskusi refleksi.

Tujuan dari kegiatan pengabdian kepada masyarakat ini adalah: 1) meningkatkan pemahaman guru dan kepala sekolah tentang konsep evaluasi diri dalam rangka penjaminan mutu internal sekolah/madrasah, 2) meningkatkan keterampilan guru dan kepala sekolah dalam mengisi instrumen akreditasi sebagai bagian dari pelaksanaan evaluasi diri sekolah/madrasah, dan 3) meningkatkan kesadaran guru dan kepala sekolah tentang pentingnya penjaminan mutu internal melalui evaluasi diri sekolah/madrasah yang dilakukan secara berkesinambungan.

\section{Metode Pelaksanaan}

Permasalahan mendasar yang diketahui melalui observasi dan wawancara di Kelompok Kerja Madrasah (KKM) Aliyah Wilayah IV Lombok Barat adalah adanya kesulitan dalam pengisian instrumen akreditasi. Selain itu juga adalah belum meratanya sosialisasi yang dilakukan oleh BAN S/M dan BAN S/M Propinsi terhadap instrumen akreditasi yang relatif masih baru ini. Untuk memecahkan permasalahan tersebut di atas maka dilaksanakan kegiatan pengabdian pada masyarakat ini dalam bentuk pelatihan dan pendampingan dengan langkah-langkah sebagai berikut: 1) memberikan pemahaman tentang konsep evaluasi diri dalam rangka penjaminan mutu internal dan sosialisasi instrumen akreditasi dengan metode ceramah, tanya jawab dan diskusi, 2) memberikan pelatihan pengisian instrumen akreditasi yang dikembangkan oleh BAN S/M, dan 3) melakukan pendampingan dan refleksi terhadap hasil kerja guru dan kepala sekolah dalam pengisian instrument akreditasi.

\section{Proses dan Hasil}

Kegiatan tahap pertama dilaksanakan pada hari Selasa 18 September 2018 diisi dengan penyajian materi yang meliputi: 1) Pentingnya 
Penjaminan Mutu Internal dan Eksternal pada Satuan Pendidikan (disampaikan oleh Dr. A. Hari Witono, M.Pd), 2) Perangkat Akreditasi (disampaikan oleh Dr. Sukardi, S.Pd.,M.Pd) dan, 3)

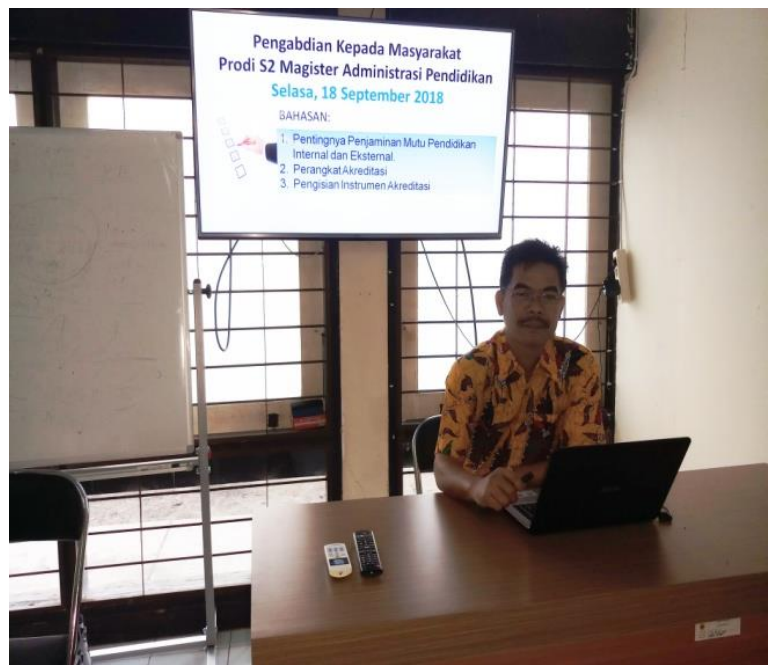

Pengisian Instrumen Akreditasi (disampaikan oleh Dr. Agus Ramdani, M.Sc). Dokumentasi kegiatan pada tahapan ini disajikan pada Gambar 1 berikut.

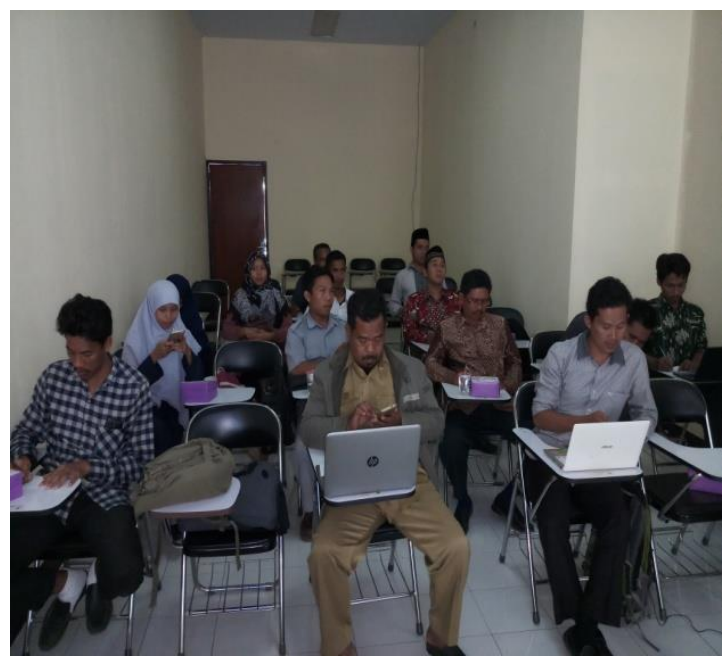

Gambar 1. Foto kegiatan penyajian materi oleh Tim pengabdian kepada masyarakat.

Kegiatan tahap pertama ini diikuti oleh 18 orang peserta yang terdiri atas Kepala Madrasah, Wakil Kepala Madrasah, Guru, dan TU/Operator yang tergabung dalam KKM Wilayah IV Kabupaten Lombok Barat. Peserta sangat antusias mengikuti kegiatan, terbukti dari munculnya pertanyaan-pertanyaan yang diajukan baik dalam diskusi kelas kepada tim pengabdian pada masyarakat maupun antar sesama peserta dalam aktivitas diskusi kelompok.

Hasil yang diperoleh pada tahap ini memperkuat anggapan yang melatar belakangi pentingnya pengabdian pada masyarakat ini dilakukan yakni tentang lemahnya penguasaan/pemahaman peserta tentang instrumen akreditasi yang dikembangkan oleh BAN S/M. Fakta tentang hal ini terungkap dari proses dan hasil diskusi yang terjadi dalam kelas ketika berlangsungnya sosialisasi.

Pada sesi ini pula muncul pertanyaanpertanyaan terkait dengan kaitan antara akreditasi dengan penyelenggaraan pendidikan. Soedjiarto (2005) menyatakan bahwa akreditasi mengarah kepada terjaminnya setiap warga negara untuk memperoleh pendidikan yang bermutu. Berdasarkan tujuan ini muncul keperluan akan adanya standar mutu untuk dapat dijadikan sebagai acuan. Peraturan Pemerintah Nomor 19 tahun 2005 tentang Standar Nasional Pendidikan telah menetapkan delapan (8) komponen sebagai dasar untuk menetapkan kelayakan suatu satuan/program pendidikan apakah mampu memberikan pendidikan yang bermutu, yaitu: Standar Isi, Standar Proses, Standar Kompetensi Lulusan, Standar Pendidik dan Tenaga Kependidikan, Standar Sarana dan prasarana, Standar Pengelolaan, Standar Pembiayaan, dan Standar Penilaian Pendidikan.

Kegiatan standarisasi di negara maju, dilaksanakan secara terbuka dan transparan. Misalnya di Amerika, dalam menyusun dan menetapkan garis-garis besar standar kurikulum sekolah serta instrumen yang digunakan untuk tingkat nasional melibatkan beberapa organisasi sesuai dengan bidang keahlian mata pelajaran. (U.S. Education Standard, 2008). Setiap sekolah berkewajiban untuk mengembangkan kurikulum berdasarkan standar yang telah ditetapkan dan selanjutnya digunakan sebagai acuan dalam penyelenggaraan ujian nasional (Nationwide Exam). Negara Georgia menerapkan delapan (8) Standar untuk Pendidikan Dasar dan Menengah yaitu kurikulum, pembelajaran, penilaian, perencanaan dan organisasi, peserta didik, dukungan dan keterlibatan keluarga dan masyarakat, pengembangan profesi, kepemimpinan, dan budaya sekolah. (Bostingl, 2001). Sedangkan di 
Inggris, terdapat suatu badan standarisasi/ akreditasi yang bernama OFSTED (Office for Standards in Education), yang tugasnya adalah melakukan kontrol standar melalui "school inspection" dengan melaksanakan evaluasi dan supervisi, menentukan pencapaian peringkat pada setiap sekolah dan memberikan rekomendasi kepada sekolah yang bersangkutan serta kepada pemerintah tentang upaya yang harus dilakukan dalam rangka peningkatan mutu pendidikan. Badan ini bertanggung jawab langsung kepada parlemen dan dipimpin seorang ketua yang diangkat oleh "Queen; Her Majesty Inspectors", (Waskito, 2005).

Pada saat sesi diskusi muncul pula pertanyaan tentang peranan akreditasi. Peranan akreditasi sangatlah krusial yaitu untuk memperoleh gambaran atau profil yang nyata tentang kelayakan suatu satuan/program pendidikan diukur dari standar mutu yang telah ditetapkan. Hasil penilaian terhadap tingkat kelayakan dan kinerja satuan pendidikan ini akan bermakna: 1) bagi penyelenggara satuan pendidikan untuk berupaya memperbaiki/meningkatkan tingkat kelayakannya; 2) bagi masyarakat agar dapat memilih sekolah yang memadai bagi putra-putrinya dan sekaligus bersama-sama berupaya meningkatkan kelayakan satuan pendidikan yang bersangkutan; 3) bagi instansi terkait untuk dapat menyusun program yang tepat sasaran dalam upaya memperbaiki kelayakan dan kinerja satuan pendidikan agar dapat meningkatkan mutu layanan yang bermakna pada penjaminan dan peningkatan mutu pendidikan.

Kaitan antara penjaminan mutu dan peningkatan mutu juga menjadi materi yang dibahas pada sesi diskusi. Penjaminan mutu (Quality Assurance) dan peningkatan mutu (Quality Improvement) merupakan dua hal yang saling berkaitan erat. Upaya menciptakan pendidikan yang bermutu harus dilakukan secara sistematis diawali dengan pengumpulan data, pemrosesan data, analisa data, pelaporan, dan rekomendasi yang ditindak lanjuti dengan implementasi. Pengumpulan data secara akurat dan proses analisis yang dilakukan secara professional serta laporan yang dapat dipercaya atau akuntabel adalah merupakan bentuk penjaminan mutu. Sedangkan program pengembangan dan implementasinya yang didasarkan atas rekomendasi dari laporan adalah merupakan upaya peningkatan mutu (McGinn and Borden, 1995). Sejalan dengan hal tersebut telah dikembangkan program aplikasi sebagaimana dilaporkan (Subangun dan Isroin, 2018) bahwa Program aplikasi EDS model EMI memiliki beberapa kelebihan dalam hal kemudahan, kecepatan, dan ketepatan. Kelebihan-kelebihan yang dimaksudkan adalah semua komponen sekolah bisa melakukan tanpa banyak kesulitan, EDS bisa diselesaikan. dalam waktu relatif yang tidak lama, dan semua aspek standar pendidikan mampu dievaluasi.

Setelah sesi diskusi selesai, dilanjutkan dengan menelaah instrumen akreditasi jenjang SMA/MA secara berkelompok. Instrumen akreditasi yang ditelaah adalah dokumen resmi yang dikeluarkan oleh BAN S/M pada tanggal 3 April 2017 berdasarkan Peraturan Menteri Pendidikan dan Kebudayaan Nomor 004/H/AK/2017 tentang Kriteria Perangkat Akreditasi SMA/MA.

Mekanisme interaksi dalam kegiatan sesi ini dimulai dengan kegiatan curah pendapat dan diskusi mengenai keterkaitan antara instrumen akreditasi, petunjuk teknis pengisian instrumen akreditasi, dan instrumen pengisian data dan informasi pendukung. Dalam prakteknya, sekolah/madrasah mengisi instrumen pengumpulan data dan informasi pendukung yang pada saatnya nanti akan digunakan oleh asesor sebagai acuan untuk validasi dan verifikasi ketika kegiatan visitasi. Peserta mendalami cara pengisian instrumen tersebut dan mendiskusikannya bersama narasumber. Analisis keterkaitan ketiga komponen perangkat akreditasi tersebut menjadi bahan diskusi selanjutnya yang dapat dikerjakan di sekolah/madrasah. Analisis dilakukan mengacu pada lembar kerja yang telah disiapkan sebelumnya berisikan komponen standard, nomor butir, hasil telaah terhadap instrumen, petunjuk teknis pengisian instrumen, dan IPDIP, serta saran solusi jika ada permasalahan terkait dokumen-dokumen tersebut.

Hasil telaah yang menjadi sumbang saran dari peserta antara lain: 1) daftar pertanyaan yang relevan masih perlu dikembangkan untuk melengkapi petunjuk teknis pengisian instrumen akreditasi, 2) pengecekan isian data pada instrumen pengumpulan data dan informasi pendukung perlu dilakukan secara teliti, 3) perhitungan jumlah terkait dengan perangkat pembelajaran yang dikembangkan oleh guru di sekolah perlu mencantumkan formula yang sederhana dalam 
dokumen instrumen pengumpulan data dan informasi pendukung.

\section{Kesimpulan}

Kesimpulan yang dapat ditarik dari proses dan hasil pengabdian pada masyarakat ini antara lain ialah: 1) Guru-guru dan Kepala madrasah pada kelompok kerja Madrasah Aliyah wilayah IV Lombok barat masih belum mampu menganalisis keterkaitan antara instrumen akreditasi, petunjuk teknis pengisian instrumen akreditasi, dan instrumen pengumpulan data dan informasi pendukung; 2) Kemampuan peserta untuk menganalisis ketiga komponen perangkat akreditasi ini dapat dikembangkan melalui proses diskusi dan pelatihan/pendampingan yang berkelanjutan; 3) Kesadaran dan semangat peserta untuk meningkatkan pemahaman tentang instrumen akreditasi merupakan modal utama untuk melakukan evaluasi diri sekolah dalam upaya peningkatan mutu pendidikan berkelanjutan.

\section{Saran}

Berdasarkan proses dan hasil yang diperoleh dalam kegiatan pengabdian pada masyarakat ini dapat dikemukakan saran antara lain: 1) perlu adanya kerjasama antara Lembaga Pendidikan Tinggi, Dinas Pendidikan, Lembaga Penjaminan Mutu Pendidikan untuk mengawal penjaminan mutu (Quality Assurance) dan peningkatan mutu (Quality Improvement) pada Lembaga pendidikan dasar dan menengah secara berkelanjutan, 2) Kerjasama yang berkelanjutan dapat dalam bentuk pertukaran informasi, pelatihan teknis, maupun pendampingan yang mengarah pada penjaminan maupun peningkatan mutu pendidikan.

\section{Ucapan Terimakasih}

Dengan terlaksananya kegiatan pengabdian pada masyarakat ini, disampaikan ucapan terimakasih kepada Rektor dan Ketua LPPM Universitas Mataram yang telah memberikan dana DIPA BLU dengan Surat Perjanjian Nomor 1320/UN18/LPPM/2018. Ucapan terima kasih juga disampaikan kepada Ketua Kelompok Kerja Madrasah (KKM) Aliyah Wilayah IV Lombok Barat yang telah mengkoordinir seluruh peserta (Kepala Madrasah, Guru, Operator) sehingga kegiatan ini dapat terlaksana sesuai dengan yang direncanakan.

\section{Daftar Pustaka}

Bonstingl, John Jay. 2001. Schools of Quality. Thousand Oaks, Califirnia: Corwin Press, Inc.

McGinn, N., \& Borden, A. 1995. Framing Questions Constructing Answers, Linking Research with Educational Policy for Developing Countries.Harvard: BookCrafters Inc.

Peraturan Pemerintah No. 19 Tahun 2005, tentang Standar Nasional

Pusat Pengembangan Tenaga Kependidikan. 2015. Peningkatan Kompetensi Kepala Sekolah Dalam Mengelola Kurikulum: Evaluasi Diri Sekolah. Jakarta: Kementerian Pendidikan dan Kebudayaan.

Soedjiharto. 2005. Pokok-Pokok Pikiran tentang Akreditasi Nasional Sekolah dalam Rangka Pembangunan Bangsa dan Kaitannya dengan Upaya Penjaminan Mutu Pendidikan serta Prosedur Pelaksanaannya, Jakarta: Depdiknas. Disajikan dalam Rapat Koordinasi PPPG dan LPMP, tanggal 27 Mei 2005.

Subangun dan Isroin, L. 2018. Penerapan Evaluasi Diri Sekolah Dasar Model EMI di Kabupaten Ponorogo Tahun 2017. Jurnal Pendidikan Edutama. Vol. 5 No.1 Hal. 81-90.

Undang-Undang No. 20 Tahun 2003, tentang Sistem Pendidikan Nasional.

U.S. Department of Education, U.S. Education Standard. 2008. National Standard. Washington,D.C.: Education World. Diakses 20 Oktober 2008, dari http://www.education-world.com.

Waskito. 2005. Paradigma Kualitas Pendidikan dan Sistem Penjaminan Mutu. Jakarta: Depdiknas. 